\title{
Natureza, território, civilizaçãa e modernidade e a construção da nação nos livros didáticos de geografia da Primeira República
}

\section{Nature, territory, civilization and modernity and the nation-building in Geogra- phy textbooks of First Republic}

Naiemer Ribeiro de Carvalho *

\section{Resumo:}

Esse artigo analisa a presença de uma ideologia nacional e a compreensão de como se formou e se criou uma ideia e imagem de Brasil nos livros didáticos de geografia do ensino secundário na Primeira República (1889-1930), período decisivo à afirmação e definição da nacionalidade brasileira no qual a unicidade e a centralização do território eram valores imprescindíveis. O cabedal teórico-metodológico mobilizado para a compreensão do espaço e da realidade vivida à época e registrada nos livros didáticos de geografia se apoiou na análise histórica do período, da geografia escolar e do pensamento geográfico. Desta conjunção foram extraídas as categorias de análise: Natureza e Território; e Civilização e Modernidade.
* Mestre em Geografia pela Universidade Federal de Minas Gerais (UFMG). Técnica em assuntos educacionais na UFMG.

\section{Abstract:}

This article analyzes the presence of a national ideology and understanding of how it formed and created an idea and image of Brazil in high school geography textbooks in the First Republic (1889-1930), a period crucial to the statement and definition of nationality Brazil, in which the unity and centralization of the territory were essential values. The theoretical and methodological leather mobilized for the understanding of space and the living reality at the time and recorded in textbooks of geography was based on the historical analysis of the period, the school geography and geographical thought. This combination were extracted categories of analysis: Nature and Territory; and Civilization and Modernity.

\section{Palavras-chave:}

Geografia, ideologia, discurso, nacionalismo, escola

Key-Words:

Geography, ideology, discourse, nationalism

school 


\section{INTRODUÇÃO}

$\mathrm{O}$ estudo sobre a História da Geografia no Brasil têm alcançado diversos avanços nos últimos anos. Neste sentido, estudar e pesquisar História da Geografia Escolar no Brasil é de extrema importância, pois a Geografia Escolar cumpriu um importante papel na sistematização e consolidação do conhecimento geográfico, antes mesmo de sua institucionalização, que no Brasil veio a ocorrer em 1934 com a criação do primeiro curso de Geografia na USP.

Além disso, a Geografia Escolar cumpre um papel central no processo de formação da nação e disseminação da ideologia nacional no país. A ideologia é o conceito que nos auxiliou a entender este processo de formação de subjetividades que estão vinculadas a grupos maiores e classes hegemônicas que por vezes não refletimos sobre elas. Constituímos nossa identidade baseados no fato de sermos 'brasileiros', e ser brasileiro carrega um conjunto de significações que muitas vezes assumimos em pensar. Assim também é com os mitos e com a história do país. Estes mitos e símbolos estão carregados de uma concepção do que deveríamos ser, e adotá-los sem reflexão, faz parte deste condicionamento.

A construção da ideologia nacional - assim como os sentidos e significados que a nação ${ }^{1}$ adquire na história do Brasil- e a forma como ela produz sentidos a partir do discurso nacionalista nos livros didáticos de geografia da Primeira República (18891930) é o que se buscou compreender na pesquisa que orienta este artigo. Pretendeu-se ainda compreender qual foi sua relação com a consolidação da geografia enquanto campo científico e escolar a partir de então.

Desta forma, o percurso que traçamos aqui nós dá uma abordagem sobre a história do pensamento geográfico, que é a relação da construção deste pensamento no Brasil com a ideologia nacional, o discurso nacionalista e a escolarização ${ }^{2}$. Esta abordagem não pretendeu ser totalizante, entendemos a multiplicidades de questões que se relacionavam, e até hoje se relacionam, com a geografia naquele período.

No Brasil, a construção do Estado-Nação necessitou de um período de quase um século: o sé- culo XIX. Após a Independência é que se iniciam os processos de formação da identidade nacional e de consolidação do Estado. Durante o Império, o que se viu foram estratégias que buscavam, desde a manutenção da unidade do território, da língua até a implementação da escola pública. As tentativas de construção da nacionalidade, até então, concentravam-se nas mãos de poucos letrados, muitas vezes, ainda no nível da literatura nacional. A consolidação destas e de outras estratégias de afirmação da nacionalidade ocorreu somente com o advento da República em $1889^{3}$. Esta consolidação não significou, no entanto, a finalização desse processo. Ao contrário, este processo permanece até os dias atuais.

Na Primeira República, o próprio Estado se empenhou na construção de um projeto de nação e colocou a educação como um dos principais pilares para a circulação destas novas ideias. Assim, a escola passou a ter um papel fundamental na formação dos 'brasileiros'. E as disciplinas escolares, como é o caso da Geografia, da História e da Língua Portuguesa, estiveram intimamente envolvidas com esse processo.

É um momento em que se pode perceber em riqueza de detalhes, nos debates da época e nos registros de tempos sobrepostos, o processo de produção de sentidos. Os livros didáticos, não somente enquanto textos, mas enquanto acesso a esse discurso, registraram esta sobreposição de tempos em que convivem elementos residuais e progressistas, ainda sem hegemonia social.

Neste período, a ideia de civilização passa a fazer parte deste processo, como um ideal, fortemente demandado de fora, a ser alcançado. Para chegar à civilização, no entanto, havia alguns impedimentos, a nação ainda não estava plenamente constituída e a existência da escravidão era uma sombra neste processo. Como disseminar essas discussões para além dos debates intelectuais? Uma das respostas dadas pelo Estado foi através da escolarização.

Estes elementos e outros elementos que veremos a seguir eram debatidos pela elite letrada do período e apareceram também nos livros didáticos de geografia. Pretendia-se uma educação cívico-patriótica, que ensinasse aos cidadãos o que era ser brasileira e os valores e símbolos do novo regime 
(GOMES, 2009). A história da Geografia enquanto disciplina escolar também nos auxiliou neste processo. Pudemos constatar uma relação entre a sua constituição enquanto disciplina escolar oficial e o período em que se começa a ser discutida a nação no Brasil. Inicialmente com a criação do Colégio Pedro ll esta relação ainda não se demonstrava diretamente nos conteúdos, apenas em sua própria oficialização. A partir da década de 1850 , esta relação se estabelece também com o currículo e o conteúdo, instituindo oficialmente a Geografia e a História do Brasil. O objetivo da escola não era somente a disseminação da nação, mas também o aperfeiçoamento do individuo ${ }^{4}$.

A geografia, que ainda não era institucionalizada no país, já possuía há mais de um século uma participação direta no cotidiano da nação, seja através dos institutos e sociedades, como o Instituto histórico Geográfico Brasileiro (IHGB) desde 1838, seja como disciplina escolar oficial com o currículo regulamentado e centralizado desde a criação do Colégio Pedro II em 1837. Por isso, podemos afirmar que tanto os conhecimentos produzidos nos institutos quanto os produzidos na disciplinar escolar, participaram da consolidação e sistematização do conhecimento geográfico no Brasil, culminando em sua institucionalização na década de $1930^{5}$.

\section{OS LIVROS DIDÁTICOS DE GEOGRAPHIA}

Os livros didáticos, que seguiam o currículo oficial, foram um importante instrumento da padronização do ensino ${ }^{6}$. Com eles, os professores e alunos de qualquer parte do país tinham acesso ao currículo oficial. Os autores buscaram enquadrá-los às influências externas de cada um dos campos científicos e à realidade brasileira, buscando com isso a formação dos cidadãos brasileiros. Com a expansão do ensino neste período, as editoras possuíam um grande número de livros didáticos em seus catálogos permitindo ampla circulação no território ${ }^{7}$. E a imagem de Brasil elaborada por eles, poderia assim, formar as novas gerações em várias regiões do país.

Os livros que fazem parte desta pesquisa foram fruto de uma longa busca por acesso a um material tão raro. Raro, não por sua escassez, poucas edições ou distribuição limitada. Alguns perma- neceram nos bancos das escolas por décadas. Sua raridade advém justamente desta especificidade, serem livros didáticos, materiais descartáveis, pouco valorizados. Buscamos por autores considerados importantes para o período, como Delgado de Carvalho, Horacio Scrosoppi e outros. Os livros analisados foram (em ordem cronológica de publicação):

- Curso Methodico de Geographia Physica, Política e Astronômica: Composto para uso das Escolas Brasileiras, de Joaquim Maria de Lacerda, 1895, 6a Ed;

- Noções de Geografia do Rio grande do Sul, Brazil e Globo Terrestre, de Affonso Guerreiro Lima, 1911;

- Geographia especial ou Chorographia do Brazil, de Carlos de Novaes, 1912;

- Geographia do Brasil, de Carlos Miguel Delgado de Carvalho, 1927, $3^{\text {a }}$ Ed. (sendo a primeira edição de 1913).

- Lições de Chorographia do Brasil, de Horacio Scrosoppi, 1922, 4a Ed.

- Noções de Geografia: Curso complementar-I Parte, também de Affonso Guerreiro Lima, do ano de 1935;

A análise dos conteúdos dos livros possuiu um foco específico. O objetivo da pesquisa foi identificar a ideologia nacional nos livros didáticos de geografia deste período. Sendo assim, o que se buscou analisar foi o discurso nacionalista, que no período, tinha como base um discurso sobre a civilização e sobre o progresso.

Dos livros analisados pudemos perceber uma dificuldade em absorver as inovações do conhecimento científico e pedagógico produzidas no exterior e, em parte, aqui. Nesse sentido, o livro de Delgado de Carvalho (1927) se destaca do restante, pois embora alguns autores tentassem incluir algum tipo de renovação, os conteúdos de seus livros em muito ainda se baseava no arranjo discursivo mnemônico (LOURENÇO, 1996). A sistematização do conhecimento geográfico também estava em curso, pois na estrutura dos conteúdos utilizada pela maioria dos autores analisados, o recorte eram os estados brasileiros, e não temas geográficos. Capítulos continham definições geográficas superficiais seguidas da divisão por localização. Esta divisão também indica a importância que as divisões jurídico-administrativas fo- 
ram tomando na sociedade moderna, ou seja, do próprio Estado-Nação, pois é a partir delas que se organizam as sociedades e se estabelecem acordos entre elas.

Da leitura e análise dos livros, tendo em vista a relação entre o conhecimento geográfico veiculado, o contexto republicano, a ideologia nacional e o discurso nacionalista retiramos nossas categorias de análise: a Natureza e o Território; a Civilização e a Modernidade; e o Povo e a Cidadania8 .

\section{NATUREZA ETERRITÓRIO}

A categoria Natureza e Território contem os discursos que recorrem em seus conteúdos à evocação das qualidades da natureza e à ocupação e povoamento do território a fim de compor as ideologias nacionais do período republicano. Por se tratar de um tema amplo, decidimos subdividi-lo em dois grandes grupos:

\subsection{A exaltação da natureza:}

Presente desde o período colonial, permanecendo no período imperial e republicano como uma ressonância, uma memória persistente. Desde a descoberta e da carta de Pero Vaz de Caminha, a ideia da natureza como paraíso ou inferno terrestre esteve presente em vários registros, como nos relatos de viajantes.

Em um trecho do livro de Lacerda (1895), pontuado pelo autor como Producções, contém em sua introdução, claro apelo nacionalista, assentado na ideia de paraíso terrestre:

O Brazil é um dos paízes mais favorecidos da natureza, que parece ter-se esmerado em prodigalisar-lhe seus dons. Assim possue elle immensos rios e os mais bellos portos do mundo, a situação geographica mais adequada para o commercio universal, uma fertilidade exuberante, uma riqueza em mineraes e vegetaes sem rival (LACERDA, 1895, p. 334).

Esta ideia ou ideal de Brasil estará presente nos tópicos que tratam de cada um dos estados. Nesses, porém, aparece na descrição das qualidades naturais dos estados e na omissão de possíveis conflitos e adversidades.

Também aparecem neste quesito o mito da fertilidade do solo, em alguns momentos exaltada, em outros, rechaçada através da defesa da utilização correta das técnicas de agricultura. No livro de Novaes (1912), a exaltação da natureza ocorre em diversos trechos e possui uma particularidade: a recorrência ao mito da fertilidade. A fertilidade do solo é uma forma clássica de exaltação da natureza e remete ao interdiscurso colonial. No capítulo sobre o estado do Amazonas, o autor faz uma exaltação à variedade da flora e da fauna local: "E que variedade de fructos, que interminável celleiro pendurado das arvores a desafiar o apetite do viandante! Tudo se acha á vista e ao alcance do homem!" (NOVAES, 1912, p.71). O mito da fertilidade é novamente reforçado: "Do seio da própria terra, com pequeno trabalho, brotam as raizes e batatas, que produzem fecula, arroz, milho, café, canna de assucar, tabaco, cacáo e todos os fructos da natureza tropical." (NOVAES, 1912, p.72).

No livro de Scrosoppi (1922), a exaltação da natureza aparece também relacionada ao mito da fertilidade, o que sugere uma exploração possível de se fazer no presente e um futuro garantido aos ocupantes, como podemos verificar no tópico sobre a agricultura:

\begin{abstract}
O Brasil baseia sua fonte principal de riqueza na agricultura, que é o campo da actividade da maioria de seus habitantes. Nenhuma região do mundo é capaz de offerecer ao trabalho do homem terrenos mais vastos, mais fecundos e ao mesmo tempo mais productivos que o Brasil, cuja topographia, abundancia de rios, diversidade de climas são circumstancias summamente favoraveis para produzirem abundantes messes, que compensam larga e generosamente o cultivador (SCROSOPPI, 1922, p. 100).
\end{abstract}

O único dentre os livros analisados em que a natureza não aparece sob a forma da exaltação é o de Delgado de Carvalho (1927). Nesse livro, as descrições sobre a natureza estão relacionadas com o escopo teórico da geografia física e todas elas possuem relações com os tipos de produção e possibilidades de exploração dos recursos pelo país para que se alcance o progresso:

\footnotetext{
A fertilidade de uma região depende não sómente da composição das terras desta região, como também do clima de que goza e especialmente do regimen de suas chuvas. A fertilidade extraordinária de nosso solo é, sob este ponto de vista, mais proverbial do que real. As terras silico-argilosas de S. Paulo, por exemplo, pobres de cal, seriam, segundo dizem competentes agronomos, pouco ferteis se não fossem tão providencialmente irrigadas.

O que caracteriza melhor nosso sólo é sua espessa camada
} 
de terra aravel. A agricultura européa dispõe de terras uteis cuja espessura média é de 60 centimetros; a agricultura brasileira, pelo contrario, vê a espessura média de suas terras oscilar entre 1 e 2 metros, alcançando commummente 3 metros e mais. Ha camadas de terra rôxa que medem cerca de 20 metros (CARVALHO, 1927, p. 146).

Após essa desmistificação da fertilidade do solo brasileiro, Delgado apresenta os tipos de solo e suas principais características e cultivos adequados. Embora os outros autores cultuem a técnica como um caminho para o progresso do país, somente Delgado de Carvalho ousou utilizá-la para quebrar com um dos mitos mais antigos e resistentes que pertence à nossa memória e ao imaginário social.

Outra forma de exaltação da natureza, agora sob o verniz da ciência, aparece nos trechos sobre a hidrografia. São enumeradas as bacias, seus principais rios, suas características de extensão e volume d'água, e uma lista de seus afluentes. Esses dados permitiam incutir a perspectiva de que o potencial hídrico apoiará no futuro o progresso do país pautando a matriz energética na força hidráulica.

No livro de Lima (1935), a hidrografia é exaltada através da quantidade: o autor fornece uma extensa lista com os nomes dos afluentes dos rios principais das bacias. Mas a forma em que essa exaltação aparece mais ostensivamente é na presença de quatro fotografias de quedas d'água e saltos em páginas seguidas (LIMA, 1935, p. 86-87-90-92). As legendas são "Quéda no rio Ivahy", "O salto do Inferno, no rio Santa Cruz", "A cascata Herval, no município de São Leopoldo, com 105 metros de altura", e "Cascata do arrio Feitoria, com $47 \mathrm{~m}$. de queda". O potencial para a produção de energia hidráulica de cada rio é, inclusive, apresentado pelo autor.

\subsection{O território}

As representações sobre o território foram sendo disseminadas no discurso nacionalista desse período e orientaram a sua produção. Moraes (1988) classificou esse conjunto de representações sobre o espaço como ideologias geográficas. Dentre essas representações, que carregam ainda muito da ideia de conquista, podemos perceber:

a) A expansão do território, sua ocupação e a consolidação da ocupação das fronteiras: informa- ções com o objetivo de afirmar os limites do país e despertar o ideário de segurança nacional; a evolução da ocupação e a história do povoamento, e a origem das nomenclaturas dos locais aparecem também nos livros didáticos. O histórico dos itinerários das expedições, textos de geógrafos, naturalistas, narrativas de viajantes, engenheiros e técnicos eram registros utilizados pelos autores para a escrita do material escolar. Por isso, os livros contavam com descrições minuciosas, dados estatísticos, atlas, mapas, itinerários que vão mostrar o espaço geográfico como espaço nacional, buscando estabelecer um patrimônio geográfico, descobrindo o território pela história.

No livro de Lacerda (1895), todos os continentes, os países e os estados brasileiros têm na sua apresentação um histórico sobre o povoamento, a colonização e a definição de fronteiras de cada um desses lugares. Na parte relacionada ao continente americano e dedicada aos Estados-Unidos do Brazil, o autor dedica duas páginas e meia para apresentar sua Historia. Nesses parágrafos, pode-se perceber um sentido de delimitação do campo da geografia, pois o foco dessa recuperação histórica é o território. $\mathrm{O}$ autor descreve a chegada dos portugueses como uma "descoberta casual", difundindo um mito até hoje encontrado nos livros didáticos, mas; também enumera as tribos indígenas que então ocupavam o território e todos os eventos históricos mais importantes até a Proclamação da República.

Lima, no livro de 1911, não descreve a história da ocupação nem do território brasileiro, nem do Rio Grande do Sul. Limita-se a detalhar as fronteiras do estado e a um comentário sobre a origem de Porto Alegre. Já no livro de 1935, as questões fronteiriças são apresentadas pelo autor, que cita trechos de outros autores para justificar sua definição. Isso pode indicar conflitos fronteiriços recentes naquela data ou ainda existentes na região sobre os limites com o Estado de Santa Catarina com o Uruguai e com a República Argentina.

No livro de Delgado de Carvalho (1927), a questão das fronteiras, dos tratados e do histórico da consolidação do território mereceu destaque já nas primeiras páginas. $\mathrm{O}$ autor dedica um tópico com 14 páginas às fronteiras e o divide segundo os parágrafos como § 1 - Typos de fronteiras, onde Del- 
gado explica o que são as fronteiras, como conceito geográfico e sua tipologia utilizando a concepção de Camille Vallaux, e classifica as fronteiras brasileiras como "fronteiras esboçadas" e "fronteiras vivas", rechaçando a antiga classificação entre fronteiras naturais e artificiais, já que ambas seriam artificiais (mesmo as demarcadas por acidentes naturais), pois são instituídas pela sociedade. (CARVALHO, 1927, p. 8)

Outra questão recorrente é a ocupação e a exploração dos recursos da região central e norte do país, uma preocupação desse momento, pois essa exploração poderia fornecer as riquezas necessárias para o financiamento do progresso. O pressuposto é que "a lei natural do progresso é a expansão dos povos." (DUTRA, 2002, p.169). Talvez por isso, o estado do Amazonas e os demais da atual Região Norte, tenham merecido destaque nas descrições dos autores. Tal destaque é relativo não só à riqueza de detalhes descritivos e imagens, como também ao fato de que nos livros que contém uma estrutura de divisão do conteúdo pautada pelos estados brasileiros, como são os livros de Lacerda (1895), Novaes (1912) e Scrossopi (1922), o Estado do Amazonas é o primeiro a aparecer da lista dos estados brasileiros, ficando após o Distrito Federal apenas no livro de Novaes (1912).

b) A integração do território: Com os obstáculos naturais e de ordem política, cultural e histórica entre as regiões, a integração do espaço nacional tornou-se um desafio. Esse, talvez, seja o discurso diretamente relacionado ao seu contexto de produção mais enfático e presente em todos os livros analisados. A questão da integração do território tornou-se urgente para o progresso da nação. $O$ patrimônio cultural e natural das particularidades regionais estava sendo valorizado, mas os obstáculos naturais da integração demandavam uma solução.

E essa integração tinha que se dar em dois níveis: a integração política, alinhando os governos estaduais ao governo federal; e a integração do território, através dos mais diversos recursos materiais de linhas de comunicação e transportes. Nesse sentido, incluiu-se também a solidariedade às áreas econômicas menos favorecidas e uma divisão territorial do trabalho, pois o ideal era o da homogeneização do progresso no território.
A integração entre as regiões também tinha um viés econômico de aumento da produção, seja agropecuária, mineral ou extrativista. Também intencionavam a diversificação da produção que nesse período centrava-se no café e na borracha.

E foi em torno da integração econômica do território que convergiram os discursos de todos os autores. Os meios de transporte e de comunicação, com destaque para as estradas de ferro e telégrafos, são os principais focos dessa integração e aos poucos vão aumentando sua importância nos livros didáticos, pois representavam as grafias da modernidade e da modernização no território nacional.

No livro de Lacerda (1895), as estradas de ferro e outras vias de comunicação mereceram um tópico separado, embora o conteúdo esteja alinhado com o arranjo discursivo mnemônico. No tópico "Estradas de ferro", o autor enumera em uma longa lista as estradas de ferro já existentes, localizando também os pontos de partida e chegada. Em "Outras vias de communicação" aparece apenas como menção a existência de rios navegáveis e de portos no litoral. $O$ autor sugere em comentário serem ainda insuficientes, apenas as estradas de rodagem. Já as linhas de telégrafo elétrico são consideradas de extrema importância, pois constituem a ligação do Brasil com outros países e continentes, e também entre os estados brasileiros.

No livro de Lima (1911), a menção à estrada de ferro também é sucinta. $O$ autor, ao caracterizar as principais cidades do estado do Rio Grande do Sul, apenas menciona aquelas que possuem estações de trem. Na parte dedicada ao Brasil e aos demais estados, o autor cita as linhas férreas de cada um deles e sua extensão. Percebe-se já nesses livros um Brasil novo cujo desenho se faz a partir da rede de fluxos de pessoas, mercadorias e informações, infraestrutura imprescindível a um arranjo mais articulado que conecta extremos e volta ao progresso. Já no livro de 1935, Lima mencionou as estradas de ferro e linhas de comunicação no capítulo dedicado aos "Recursos econômicos". Esta alteração na alocação do conteúdo indica o aumento da importância desta discussão no período.

No livro de Novaes (1912), a integração do território também aparece ao lado da economia nacional e da modernização. No Capítulo II: Parte 
economica e industrial do Brazil a integração do território recebeu três tópicos: Vias de communicação, Estradas de ferro, e Telegraphos e Correios. No primeiro tópico são descritas a navegação fluvial, principalmente dos rios Amazonas e Paraná; a marítima, esta última feita por companhias estrangeiras; e a costeira, por companhias nacionais. As estradas de ferro mereceram destaque do item anterior e são descritas suas linhas e extensão $(21.580 \mathrm{~km})$. No último tópico, o autor, além das duas linhas telegráficas existentes e do cabo transatlântico, menciona o serviço radio-telegraphico já em funcionamento no Brasil, importante para os lugares onde não há linhas telegráficas, como em Fernando de Noronha. Mas, é quando menciona o estado do Mato Grosso que o autor posiciona-se claramente a favor da integração e da ocupação efetiva do território:

\begin{abstract}
Si até hoje o vasto Estado de Matto Grosso não possue estradas de ferro, si lhe faltam mesmo estradas de rodagem que se dirijam até os mais afastadas pontas para ir buscar os productos da industria (...) (NOVAES, 1912, p.319)

Para Matto Grosso, mais do que para qualquer outro Estado da União Brazileira, se apresenta palpitante a necessidade de tomar mais facil o seu accésso aos imigrantes; para isso urge abrir vias de communicações. (NOVAES, 1912, p. 321)
\end{abstract}

Nesse último trecho reaparece, também, a importância da colonização para o país, desde o final do século XIX. O autor menciona que já se achava em construção uma via férrea entre a cidade paulista de Bauru e Corumbá, demonstrando a interiorização da infra-estrutura e a conquista de novos mercados.

No livro de Delgado de Carvalho (1927), a integração aparece também no capítulo dedicado à "Economia Nacional", mais especificamente no tópico "Apparelhamento econômico" definido como:

O apparelhamento economico de um paiz é o capital deste paiz que serve, directa ou indirectamente, à sua produção, como sejam: sua viação, seus portos, suas finanças, suas forças motrizes, seus meios de correspondência, etc. examinaremos aqui apenas os elementos principaes: a viação, a navegação e os portos, as finanças federaes (CARVALHO, 1927, p. 197).

O tópico "Apparelhamento economico" está dividido, então, em: 1 - Viação: Estradas, Histórico e Estado atual da viação férrea; 2- Na- vegação; 3- Portos; e 4 -Telegrapho. Uma lista de tudo de mais moderno que existia na época e que implica dizer em variedade sem, contudo, mencionar as condições de funcionamento ou precariedade. A unificação e a interligação do território associadas à produção e exploração de riquezas naturais ainda desconhecidas eram motivadoras desse investimento na viação, assim como, também, a construção de novas cidades, levando o progresso e a civilização para o interior e pontos extremos do país. Manaus é um exemplo desse ideal do progresso: cidade rodeada pela floresta e, ao mesmo tempo, marco da civilização com seus importantes monumentos e prédios modernos.

Sobre o "Estado actual da viação férrea", Delgado aponta que em 1926 a viação férrea contava com $30.635 \mathrm{~km}$ e mais $2.000 \mathrm{~km}$ em construção. A interligação dessas redes já havia sido feita na rede sul e na rede norte internamente, faltando apenas interligá-las entre si. Para o estudo da rede férrea, Delgado propõe a observação dos seguintes pontos:

a) aspecto e á importancia geral das regiões atravessadas, o
ponto de contacto com o mar; b) as principaes estradas, suas
extensões, seus recursos; c) os pontos principaes servidos
por ella, as cidades e a natureza de sua producção; d) a com-
plexidade da rêde; isto é, suas communicações com as outras
rêdes, seus projectos de prolongamentos, os pontos visados
pelos seus trilhos (CARVALHO, 1927, p. 202).

A navegação foi o único meio de transporte que uniu durante muitos séculos os principais centros brasileiros. Mesmo com a existência das estradas de rodagem e da viação férrea, a navegação ainda manteve sua importância naquela época. Delgado de Carvalho (1927) perpassa o histórico e as fases pelas quais passou a navegação mercante no Brasil: o exclusivismo colonial, o monopólio (companhias holandesas no XVIII), a abertura dos portos (cabotagem exclusiva de brasileiros), a cabotagem estrangeira (inclusive no Rio Amazonas, com elogio também ao'patriótico' Barão de Mauá), e a republicana (restitui o privilégio de cabotagem à marinha).

A abertura dos portos é considerada pelo autor um marco na história do Brasil: "É esta a 
data mais importante de nossa historia econômica: pela primeira vez o Brasil era considerado potência, e data deste dia nossa independência econômica" (CARVALHO, 1927, p. 205). A restituição do direito de cabotagem à marinha é considerada um avanço, na linha seguida pelos principais países europeus e americanos, e o aumento das toneladas transportadas nesse período é atribuído a esse fato.

No tópico "Portos", Delgado de Carvalho (1927), enumera as funções necessárias para que um porto fosse considerado moderno:

1 - Uma função regional pela qual se acha o porto ligado a seu hinterland, à zona que serve, seja para a exportação dos productos desta zona, seja para o abastecimento de mercados desta zona (CARVALHO, 1927, p.212).

As outras funções, comercial e industrial, seriam referentes ao barateamento dos custos de transporte. Essa classificação alude a influências teóricas da geografia, principalmente na função regional, destacada acima devido ao fato de conter a utilização do conceito de hinterland.

O assunto sobre a integração e as dificuldades de transportes para a economia nacional já havia sido tratado anteriormente nos tópicos sobre as produções agrícolas e a dificuldade de expandir as produções, seguindo a linha adotada pelo autor de interrelação entre os temas (CARVALHO, 1927, p. 184-6).

No livro de Scrosoppi (1922), há uma crítica ao atraso das vias de transporte e comunicação no país. Na"Vigésima Sexta Lição: Agricultura, Indústria e Commercio", o único comentário que o autor tece sobre o"Commercio interior" é:

Em geral, o commercio interno do Brasil tem grande desenvolvimento, e tende cada vez mais a expandir-se, devido às communicações fluviaes e terrestres que continuamente se vão estabelecendo em todo seu vastíssimo território. Todavia, nem todos os Estados da União gozam de tão importante beneficio e imprescindível melhoramento, havendo mesmo regiões dalguns delles que pouco prosperam commercialmente, por causa da escassez e a te falta de meios de transporte rápidos e baratos, que as ponham em contacto com os centros populosos consumidores (SCROSOPPI, 1922, p. 113).

As estradas de ferro são consideradas por
Scrosoppi (1922), o principal fator de incremento comercial. O atraso no desenvolvimento do país, comparado aos Estados Unidos, Canadá e Argentina, também é atribuído à menor extensão da rede ferroviária brasileira:

Com effeito, dotados dum território quase tres vezes maior que o da Argentina, e pouco menor ao do Canadá e dos Estados Unidos, não possuímos, entretanto, siquer um vigesimo da rêde ferroviária destes, nem igualamonos áquella.

Não há mister explicar doutra maneira, a relativa lentidão de nosso progresso material. (SCROSOPPI, 2002,p.115)

Sobre a navegação, ele a divide em marítima e fluvial. No tópico da navegação fluvial, o autor enumera os principais rios e bacias navegáveis: O Amazonas, o Paraná e o Paraguay. Os portos também estão enumerados segundo a ordem de importância, primeira ou segunda ordem, e divididos entre marítimos e fluviais, são sete páginas com as descrições dos portos de cada estado.

No tópico em que trata dos "Telegraphos", o autor utiliza-se da mesma e longa estrutura descritiva: a extensão das linhas de telégrafos, os serviços nacionais e internacionais, a "Telegraphia" sem fios e suas estações, e o serviço telefônico recém introduzido no país. Esse trecho possui dois mapas: o primeiro com o título"Mappa das linhas telegraphicas nacionaes e cabos submarinos estrangeiros"; e o segundo, "Radiotelegraphia: Repartição geral dos telegraphos" (SCROSOPPI, 1922, p. 144).

\section{CIVILIZAÇÃO E MODERNIDADE}

\subsection{A civilização, a modernidade e seus símbolos}

pA modernidade, nesse período, era sinônimo de civilização. Mais que isso, as cidades, monumentos, praças, bibliotecas, museus, jardins botânicos, representavam grafias da civilização nos trópicos, especialmente no Brasil. Aliada ao progresso e à modernidade, alcançar a civilização era um dos destaques do discurso nacionalista republicano. Nesse sentido, se fa- 
zia necessário demonstrar, através de suas cidades, o alcance do par civilização/ciência no país.

A cidade foi valorizada nos aspectos arquitetônicos, de transporte e circulação, os monumentos, as melhorias nas condições sanitárias e do controle de doenças e epidemias - nas cidades e na selva também -, as diversões e a sociabilidade urbana. A cidade aparece como uma representação, um símbolo, da modernidade da nação, medida da condição social, da prosperidade econômica e do progresso brasileiros. Por isso grande parte das ilustrações dos livros são dedicadas a elas.

Se a nação é construída internamente, afirmando sua diferença com as outras nações através da língua, cultura, literatura, povo, natureza e território, ela também é construída externamente, mostrando fazer parte do concerto internacional das nações através da adoção dos ritos do progresso, pela pratica da ciência e das artes. É a elevação do particular ao universal e as nações civilizadas deveriam participar desse universal. A República seria a patrocinadora dessa trajetória do país rumo ao concerto científico, moderno e progressista internacional. Esses elementos de destaque para a civilização, a modernidade e seus símbolos estão presentes em todos os livros analisados.

No livro de Lacerda (1895), esse discurso está presente de forma direta, desde o prefácio no qual o autor justifica o estudo da geografia como um fator de civilização:

Hoje que o estudo da Geographia vai tomando um desenvolvimento immenso em todos os paizes civilisados, que a consideram com razão um dos conhecimentos mais importantes e essenciaes para a prosperidade e força de uma nação, julgamos que também no Brazil, que se ufana de ser a primeira nação em todos os sentidos da America do Sul e uma das mais civilisadas do globo, este estudo deveria tomar maior incremento e não contentarse com os pequenos compendios que são geralmente adoptados. Sirva de exemplo a França, cujas recentes calamidades reconhecem todos serem devidas em parte aos poucos conhecimentos da Geographia; quanto porém não se applica Ella hoje a desenvolvel-os e espaIhal-os por todas as classes da sociedade! Prescindindo das grandes obras que vai diariamente publicando, que excellentes compendios são os que Ella adopta em suas escolas! (LACERDA, 1895, p. 2).
No parágrafo acima tem-se a exaltação da nação brasileira como uma das mais civilizadas do globo e a referência direta à França, como modelo. É assim que o autor demonstra o que seria o papel da Geografia, internamente enquanto estudo do território, e externamente enquanto afirmação geopolítica da importância brasileira por seu tamanho, riquezas e aspectos modernos 9 .

Em suas "Noções preliminares" há um tópico sobre os Estados de civilização. Esses eram divididos em três, segundo o modo de vida e progresso nas artes:

Os selvagens não têm outro culto senão vãs superstições; não conhecem a arte da escrita; a sua indústria reduz-se quase unicamente à pesca e À caça; são de ordinário nômades ou errantes, e formam só mui pequenas povoações. Taes são os Indígenas da América e da Oceania e os negros da África.

Os povos bárbaros ou meio-civilisados têm já um culto religioso e leis; conhecem as artes mais necessárias á vida, mesmo a da escrita; e applicam-se uns á cultura das terras, outros á criação de gado, sendo estes nômades. Taes são os Árabes, os Tártaros, os Afghans, etc.

Os povos civilisados não só conhecem perfeitamente as artes mechanicas, mas ainda cultivam as sciencias, as lettras e as bellas artes. Elles têm, por suas luzes, pela sabedoria de suas leis e por sua industria e commercio, augmentando as commodidades e doçuras da vida, e contribuindo assim para a felicidade geral (LACERDA, 1895, p. 24)

Os principais valores associados à civilização são a técnica, a ciência e as artes. A forma de governo e as leis também são outros indicadores. Por isso, o autor enumera as formas de governo que são estabelecidas somente em povos civilizados: primeiro a monarquia (absoluta ou constitucional e representativa); e segundo, a república (aristocrática, oligárquica e democrática). Aqui aparece também uma definição de confederação como uma reunião de Estados ligados a uma autoridade superior escolhida por eles.

No livro de Lima (1911), essa questão aparece como destaque dos símbolos da modernidade e da civilização nas cidades. Quando trata de Porto Alegre, por exemplo:

Tem bellos edificios, quer publicos quer particulares. É iluminada a gaz e a electricidade. Está em construcção 
uma rede de esgotos. Tem muitos estabelecimentos de instrucção secundaria e superior. [...] É o ponto de partida da viação férrea do Estado (LIMA, 1911, p. 31-2).

Assim, o autor menciona todos os municípios do Rio Grande do Sul apresentando sua população e uma característica moderna:

S. Leopoldo (15.000 hab. App., com Neustadt) cortada pelo rio dos Sinos. Costumes allemães. Bella ponte. Estrada de ferro. (LIMA, 1911, p. 33)

Pelotas (quase 50.000 hab.) importante cidade do sul. Bons edifícios. Estrada de ferro. Industriosa (LIMA, 1911, p. 37).

No livro de 1935, Lima repete a forma de caracterização das cidades rio-grandenses através da presença de símbolos da modernidade. As imagens das cidades utilizadas são do mesmo tipo, algumas até mesmo, iguais que as utilizadas no livro anterior. A diferença presente nesse livro é a menção à Exposição Estadual de 1901, em dois trechos, um sobre a variedade de vegetais, e outro sobre as coleções de insetos do estado "ostentando os mais ricos e variados especimens do reino vegetal, que, na Exposição Estadoal de 1901, figuraram em número de 839 exemplares de madeira" (LIMA, 1935,p. 88).

No livro de Novaes (1912), os símbolos da modernidade aparecem quando o autor descreve as capitais de cada um dos estados brasileiros. Cada uma delas possui uma descrição que valoriza esses símbolos e, também, imagens das suas ruas e monumentos.

Quando trata do Distrito Federal, o autor cita as principais instituições associadas à instrução: "o Observatorio Astronomico, a Biblioteca Nacional com 300.000 volumes, a Biblioteca Municipal com 40.000 volumes, o Muzeu Nacional, o Jardim Botanico" (NOVAES, 1912, p. 60). A descrição da cidade trata de uma exaltação dos avanços conquistados pela capital do país. Com 858.000 habitantes, o autor destaca ser a primeira cidade da América do Sul por seu comércio, indústria, população e instrução. Seu urbanismo também é exaltado, com suas belas e extensas avenidas, belos edifícios e instituições públicas relevantes como o Teatro Muni- cipal, a Biblioteca Nacional, os jornais, o aqueduto, o porto, reservatórios, praças e jardins, monumentos de personalidades como Duque de Caxias, José Bonifácio, etc., palácios governamentais, museus e observatórios (NOVAES, 1912, p.63). Essa estrutura é reproduzida para as outras capitais.

No livro de Delgado de Carvalho (1927), encontra-se destaque para a civilização e a modernidade com base na importância do papel da ciência. Nos tópicos da economia nacional, da agricultura, da indústria, do clima, o autor sempre ressalta a importância do conhecimento científico e da técnica, como veremos adiante. Esse enfoque científico não permitiu que o autor exaltasse as belezas e os símbolos da modernidade como fizeram os outros autores. No tópico sobre o Distrito Federal há um pequeno histórico da cidade, a sua função administrativa, área e dados sobre a população. Na parte final, no entanto, Carvalho (1927), utiliza a quantidade populacional e a presença de estrangeiros como indicadores de um caráter cosmopolita:

Estas proporções de forasteiros indicam bem o caracter cosmopolita que conserva a capital do paiz, pois já em 1849 avaliava-se em 113.000 o numero de estrangeiros e o recenseamento de 1872 contou 84.000 estrangeiros (CARVALHO, 1927, p. 141).

Seguida a essa afirmação há um gráfico populacional comparando o crescimento da população no Rio de Janeiro, em Paris, Londres e Berlim, entre 1789 e 1926. A linha do Rio de Janeiro acompanha as linhas dessas capitais da Europa civilizada, indicando uma preocupação em comparar o país com a referência europeia.

Essa comparação também pôde ser percebida quando trata das Exposições Universais. O autor criou também um tópico específico para elas. Nele, ele explica que as exposições foram criadas com o fim de propaganda econômica para aumentar o mercado consumidor de alguns países europeus:

Na segunda metade do XIX século, o desenvolvimento industrial de certos paizes europeus determinou a necessidade de serem procurados novos mercados e, para 
fins de propaganda economica, foram organizadas exposições; isto é, grandes feiras nacionaes ou internacionaes. Eram, assim, attrahidos forasteiros e commerciantes de todos os paizes resultára destes certamens productores industriaes novo surto para suas industrias (CARVALHO, 1927, p. 197).

Pode-se perceber aqui, que o valor dessas feiras não era somente simbólico, mas interferia diretamente na economia dos países. No Brasil foram realizadas as exposições preparatórias no período imperial, a Exposição Nacional de 1908 e a de 1922, comemorativa da Independência; e internacional: "Ambas tiveram por objetivo chamar a attenção do paiz e dos estrangeiros para o nosso apparelhamento economico e as nossas industrias" (CARVALHO, 1927, p. 197). Exposições parciais, ou temáticas, como as de gado e tecidos também eram comuns.

Como vimos anteriormente, o autor percebe a estrada de ferro como um elemento civilizador (CARVALHO, 1927, p. 199), que levaria a civilização para as áreas mais remotas do país. Outro indicativo da civilização, para Delgado de Carvalho (1927), estaria nos artigos de importação. Em seu tópico sobre Importações, o autor destaca:

Com o desenvolvimento da civilização no seculo XIX, foram, porém, se desenvolvendo outras necessidades: a grande indústria e o luxo crescente foram abrindo novos mercados brasileiros, por um lado, ao carvão, aos artefactos de ferro e de aço, por outro lado, aos vinhos finos, aos artigos de linho e de lã, as sedas, as perfumarias, etc. certos hábitos europeus, entre nós desenvolvidos, nos levaram a importar também productos alimenticios como o trigo, a cerveja, a manteiga, o bacalhau, que, aliás, o paiz já está apparelhado para produzir (CARVALHO, 1927, p.223).

Esse trecho dá-nos uma clara indicação de que a noção de civilização, embora relacionada ao progresso e à modernidade, relacionava-se também com os costumes e valores do moderno.

No livro de Scrosoppi (1922), também há comentários sobre as cidades e os símbolos da modernidade. Em cada uma das lições que trata dos estados brasileiros, o autor descreve as características modernas das principais cidades, especialmente das capitais no tópico " $\mathrm{Ci}$ dades Importantes". As imagens também vão demonstrar as modernas características dessas cidades. Sobre Manaus, o autor escreve:

Bella, aprazivel e prospera cidade, sede dos altos poderes do Estado. Possue importantes edificios publicos, destacando-se o Theatro, que é um dos mais bellos da America. Tem ruas e avenidas bem calçadas, jardins, magnifico mercado construido todo de ferro; museu, Gymnasio, Escola Normal e uma Universidade. (...) Por electricidade se effectua a tracção de bondes para os transportes dentro da cidade, e bem assim a illuminação desta (SCROSOPPI, 1922, p. 161-2).

\subsection{A modernização e a economia: a técnica e o progresso}

Se a civilização era o objetivo a ser alcançado, a modernização do país indicaria o caminho a ser trilhado. A técnica adquiriu um lugar central nesse processo, e a necessidade de integração do território exigia que a modernização chegasse também ao interior. A riqueza ali produzida poderia levar o país a alçar lugar dentre os países capitalistas avançados, pois a agricultura era a principal atividade econômica desse período. O progresso industrial e agrícola era concebido como uma "vitrine do progresso" para o restante do mundo.

Nesse período, além da valorização da ciência, havia também uma valorização da racionalidade instrumental que daria forma à modernização. Assim, as novas técnicas deveriam ser empregadas na agricultura, na indústria, no comércio, enfim em todas as áreas da economia nacional para gerar um maior aproveitamento e lucratividade.

O livro de Lacerda (1895), o mais antigo analisado, não possui nenhum apontamento nesse sentido. Talvez porque a própria estrutura de conteúdo não permitisse, o arranjo mnemônico é mais rígido nesse sentido, e também porque essas preocupações ainda não estivessem presentes para esse autor dentro dos conhecimentos geográficos. Como vimos, a geografia percebida como articuladora de estratégias para a modernização do território foi sendo progressivamente incorporada ao corpo teórico dos livros didáticos. Embora na prática, o conhecimento produzido já 
fosse utilizado para esse fim.

No primeiro livro de Lima (1911), também não há comentários nesse sentido. Já no segundo, de 1935, existem vários pontos em que o autor assume essa perspectiva. No capítulo em que trata do Rio Grande do Sul, aparecem apontamentos sobre a questão nos tópicos de "Recursos Naturais" (Energia hydraulica, Minerais, Vegetais, Animais) e no, de "Recursos Economicos" (Agricultura, zonas de produção, Indústria pastoril, indústrias manufactureiras, Colonização, Viação terrestre, fluvial e aerea, $\mathrm{Na}$ vegação, Portos, Commércio).

Sobre os recursos naturais, a perspectiva adotada então era a de exploração. O capítulo inicia-se com a divisão dos "productos da natureza" em três reinos: o mineral, o vegetal e o animal (a fauna e a flora). O reino mineral é detalhado com relevância para a questão econômica.

A possibilidade de gerar energia hidráulica era outro indicativo do que poderia ser a capacidade de modernização do território. $\mathrm{O}$ autor apresenta o potencial hidráulico do estado que seria de quatro saltos considerados de maior importância. Esses saltos são listados já com a capacidade de geração de energia já calculada à época. Outros saltos são também listados como de menor importância para a geração de energia hidrelétrica. Há duas fotos desses saltos nas páginas 86 e 87 , e mais duas fotos nas páginas 90 e 92.

No capítulo dos "Recursos econômicos", Lima (1935), utiliza-se de uma citação de Moreira Pinto ${ }^{10}$ para criticar o sistema atrasado de lavoura ainda existente no Brasil. Para eles, esse sistema devastaria a terra por desconhecimento de técnicas melhores:

Infelizmente o systema de lavoura é ainda muito atrasado no Brasil. O lavrador não fita a conservação da fertilidade de seu terreno, trata de tirar d'elle, ainda que por meios devastadores, tudo quanto elle puder dar em certo tempo e com pequeno trabalho. Estrumar, irrigar, drenar a terra, são cousas que o lavrador não conhece.

É cruel o meio por que se transforma a matta virgem em terra lavrada.

Primeiramente derrubam-se a machado as grandes árvores, dias depois o fogo incumbe-se de completar a devastação: é o que se chama queimada. - Moreira Pinto - Chorographia. (apud LIMA, 1935, p. 98)
Nessa citação, o autor reconhece a importância da técnica para o crescimento da atividade agrícola, mas não descreve nenhum tipo ou o modo como os lavradores poderiam acessá-las. Já a pecuária conta com um comentário elogioso do autor: "A criação de gado consiste na maior riqueza do Rio Grande do Sul, e muito tem progredido com a importação de typos selectos para o melhoramento das raças." (LIMA, 1935, p. 100). Em um trecho separado, o autor escreve sobre a indústria do charque, sua localização e até mesmo nomes de empresas. Os frigoríficos também são destacados, há inclusive uma foto de um grande frigorífico, com uma chaminé, na beira de um rio - o frigorífico Swift (LIMA, 1935, p. 103). A utilização da técnica e a atividade industrial, ligadas à principal atividade econômica, seriam o caminho para a modernização do estado.

No livro de Novaes, a modernização e a valorização da técnica também aparecem ao lado das atividades econômicas e da integração do território: "O commercio do Brazil é muito activo e florescente; vae adquirindo considerável importancia e incremento, devido ao desenvolvimento da indústria, das ferro-vias e da imigração." (NOVAES, 1912, p.40) Adiante, o autor apenas comenta a situação das atividades produtivas em cada um dos estados brasileiros. Os comentários presentes sobre os estados brasileiros são valorizados no sentido da possibilidade de utilização de vários recursos naturais e do crescimento da indústria para alçar o país rumo ao progresso e a modernização.

Delgado de Carvalho (1927) desenvolve este tema em diversos tópicos. A técnica é valorizada como um instrumento capaz de auxiliar principalmente no desenvolvimento da agricultura, e coloca, por exemplo, a importância do Serviço Meteorológico, que serviria aos maiores interesses da nação, para que através das "correlações significativas entre a producção e os agentes atmosphericos" possa-se estipular uma "estimativa de safra" (CARVALHO, 1927, p. 76). O Serviço possuiria estações meteoro-agrárias em alguns pontos do país e deveria ser facilita- 
do para todos os "bons cidadãos do paiz". Além disso, o autor exemplifica como a previsão poderia auxiliar o lavrador em cada uma das regiões do país, para cada tipo de cultivo.

No capítulo "Recursos Naturaes", a exploração dos mesmos é também considerada um indicador das possibilidades da modernização. A energia hidráulica é relatada desde a sua descoberta em meados do século XIX:

A invenção das turbinas e a invenção do dynamo e da sua reversibilidade, isto é, da sua faculdade de transformar a corrente electrica em força motriz, determinaram, na segunda parte do XIX seculo, um movimento scientifico-industrial no sentido do melhor aproveitamento da hulha branca ou energia hydraulica, offericida pelas quédas d'agua (CARVALHO, 1927, p. 98).

Por isso, as quedas d'água se tornaram um fator importante para o progresso do país e são citadas as três mais importantes: Iguaçu, Sete Quedas e Paulo Afonso. No entanto, haveria ainda um enorme potencial hidráulico não aproveitado, principalmente na porção meridional do país. Há uma tabela que compara a capacidade de geração em potências (cavalovapor) das principais cachoeiras.

No capítulo sobre a "Economia Nacional", a utilização de técnicas na agricultura recebe destaque novamente. O autor inicia esse tópico com uma citação de Oliveira Martins ${ }^{11}$ sobre a cultura racional na agricultura: Nas sociedades novas, diz Oliveira Martins, a riqueza tem
um papel mais dominante do que a sciencia e a philoso-
phia. É a iniciação pratica, depois da qual vem o labutar
das escolas e das doutrinas: é a criação da força collectiva
que precede a reação das idéas em que o homem não
encontra satisfação e nenhuma necessidade utilitaria". É
o que se deu no Brasil e em todas as sociedades ameri-
canas. A iniciação pratica foi penosa e difficil, e póde se
dizer que, em muitos pontos ainda não está terminada.
Em alguns Estados acha-se muito atrazado ainda o sys-
tema de lavouras. Para conquistar terras de cultura ás
mattas virgens, opera-se uma devastação selvagem por
meio de queimadas. Em seguida os methodos de cultu-
ra empregados são dos mais primitivos; as irrigações, as
adubações da terra são desconhecidas. Isso é o que se dá
em municipios agricolas numerosos onde ainda não pe-
netraram capitães sufficientes, actividades competentes
e uma propaganda da cultura racional. (CARVALHO, 1927,
p. 148).
E completa indicando algumas das técnicas que deveriam ser adotadas:

Porém esta primeira phase de experiencia pratica já está terminada em grande numero de Estados brasileiros, nos quaes a cultura mecânica da terra, as irrigações artificiaes, os adubos chimicos já foram adoptados, e onde já se acha organizado o trabalho (CARVALHO, 1927, p. 149).

Pode-se observar nesse trecho que além das técnicas agrícolas modernas, a organização do trabalho é considerada um fator de modernização do campo, principalmente se considerarmos que se trata de um contexto pós-abolição formal da escravatura. A divulgação dessas novas técnicas passaria por sindicatos, escolas, escolas técnicas e práticas e revistas, tanto da iniciativa privada, quanto pública:

A sciencia agrícola é ensinada, entre nós, desde o grão elementar até o grão superior, desde a escola primaria até a escola especial, por aprendizados agricolas, escolas de capatazes, escolas praticas e institutos agronomicos (CARVALHO, 1927, p. 149).

Na parte dedicada às "Industrias Extrativas", são apresentados os recursos naturais: a borracha, madeiras, erva mate e a carnaúba, e o estado atual de sua exploração e da indústria associada. A defesa da exploração das madeiras das florestas é feita, nesse período, sem nenhum pudor. A legislação que existia nos estados tratava de incentivar a exploração das madeiras. Carvalho (1927) lamenta:

Apesar de riquissimas, nossas mattas tropicaes e subtropicaes são mais interessantes para o naturalista do que para o industrial. Representam, é verdade, uma das mais importantes reservas do mundo para o abastecimento de madeiras; não offerecem, porém, as condições de facil e proveitosa exploração da matta boreal (CARVALHO, 1927, p. 186).

Assim, pode-se perceber que permanece a visão da natureza enquanto recurso e reserva para o progresso do país.

A industria manufactureira ou a atividade fabril é relatada em quatro páginas que contemplam seu histórico. No período havia uma divisão entre as atividades industriosas da mineração e da agricultura, e da atividade fabril 
em si. Nesse histórico, Delgado de Carvalho (1927), relata os eventos ocorridos nesse ramo da economia desde a colonização, inclusive a proibição da indústria pela metrópole. Somente em 1750, passam a existir as primeiras indústrias têxteis, proibidas, porém, de fabricar tecidos finos. Não obstante os tratados assinados, com a Inglaterra principalmente, surgiram fábricas de tecidos, papel, chocolate, massas e outros, no século XIX. Após 1840, começam a surgir outras fábricas que produziam para o consumo interno, como móveis, tecidos, sapatarias, cal e outros.

O autor destaca a importância das Exposições Universais para o desenvolvimento da indústria no Brasil:

De 1861 até o fim da monachia, os progressos são mais ra-
pidos e varias exposições nacionaes preparatorias de ex-
posições estrangeiras permittem seguir, imperfeitamen-
te aliás, este interessante desenvolvimento industrial. A
exposição de 1861 era preparatoria da de Londres, a de
1865 da de Paris, a da 1875 das de Vienna e Philadelphia.
Mas pouco a pouco, de enfeitadas, mas mesquinhas e
pobres, passaram a despertar maior interesses e a serem
mais representativas e reaes. Foi assim que as de 1881 e
1889, mais concorridas, ostentaram o estado exacto do
desenvolvimento fabril da capital. Entre estas duas datas
o progresso foi marcado e mais de 180.000 contos foram
empregados na industria (CARVALHO, 1927, p. 193).

O comércio exterior também aparece como um indicador dessa modernização. $\mathrm{O}$ autor dedica 13 páginas a esse tópico. Relata seu histórico, introduz a noção de política comercial protecionista e livre-cambista e também a noção de política financeira. Todas associadas à geografia:

A politica commercial de um Estado representa, por conseguinte, um papel importante na vida do paiz e por essa razão é ligada ao estudo de sua geographia econômica (CARVALHO, 1927, p. 217).

Para tal estudo, ele divide a política comercial brasileira em três fases: a colonial, a imperial e a republicana. Descreve detalhadamente cada uma dessas fases, seus tratados, principais produtos exportados e importados e os países (CARVALHO, 1927, p. 222).

Na conclusão do livro, Delgado de Car- valho (1927), posiciona o Brasil frente às "principaes potencias do globo": como um país de grande extensão territorial, que apesar do atraso na integração "se abriu à era de pleno aproveitamento e occupação integral do paiz"; possui uma população em rápido crescimento e que, em quatro anos, se comparará à da Grã -Bretanha, França e Itália, e "este crescimento é factor de contínuo progresso e nos leva, cada dia mais, a nos occupar das questões internacionaes, isto é, a estender a nossa influencia e a nossa acção"; possui uma variedade de recursos naturais, e "o aproveitamento destas riquezas fará entrar o paiz na phase da grande industrialização" (CARVALHO, 1927, p.230).

A modernização e o progresso do país são vistos sempre em relação ao contexto internacional e à importância de colocar-se bem, frente às outras nações:

Em resumo, economicamente falando e sob o ponto de vista actual internacional que serve a medir, apreciar ou aquilatar o valor economico das potencias, o Brasil ainda não está em plena exploração de suas riquezas naturais: a sua economia nacional ainda repousa sobre bases accessorias, isto é, que não constituem os alicerces definitivos sobre os quaes está destinada a assentar a sua grandeza futura (CARVALHO, 1927, p. 231).

Para alcançar essa grandeza futura, o autor sugere que se deve abandonar a ideia de uniformização, compreendendo e tratando de forma diferenciada cada uma das regiões do país, respeitando assim, suas particularidades:

Já no colégio A (público) apenas um professor abordou que ocorre já o outro professor salientou que para se trabalhar, "há muita resistência por parte de alguns colegas" não ocorrendo o ensino de forma interdisciplinar com base em Petraglia (1993) e Cascino (2003) sendo trabalhado apenas de forma pontual como já evidenciado.

As differentes regiões naturaes do Brasil estão destinadas a prosperar por processos differentes, com "politicas" distinctas: este facto que nos é dictado pela propria physiographia do paiz, tambem nos é imposto pelas tradições historicas do passado e dele resultou acertadamente a federação, a modalidade economico-politico-geographica que adoptámos (CARVALHO, 1927, p. 231). 
E para concluir, o autor escreve: "tenhamos confiança no Brasil, nos brasileiros, e nos governos bem intencionados que guiam e amparam a nação". (CARVALHO, 1927, p.233).

No livro de Scrosoppi (1922), a técnica e a modernização aparecem em alguns momentos apenas, ao lado da integração do território, dos recursos naturais e da indústria. Na questão da agricultura, por exemplo, o serviço de meteorologia aparece, ressaltando a inovação e a aplicação técnica do conhecimento científico. Os observatórios estavam presentes em quase todos os estados e tinham como claro objetivo o "louvavel e patriotico intuito de auxiliar a lavoura" (SCROSOPPI, 1922, p. 113). E fornece ainda uma planilha com a localização por estado e quantidade das estações da união, dos estados e gratuitas (SCROSOPPI, 1922, p. 114). Mas, o ensino profissional agrícola e os patronatos agrícolas eram vistos pelo autor apenas como instituições "cujo fim é transformarem em elementos uteis á sociedade centenas de menores retirados da ociosidade e do vicio." (SCROSOPPI, 1922 , p. 104).

\section{CONSIDERAÇÕES FINAIS}

A Proclamação da República inaugurou um novo período que já estava sendo delineado desde a década de 1870. É um período em que iriam se reorganizar os sentidos dados à nação. Com ela vieram novos elementos: a abolição da escravatura, a crescente urbanização e industrialização, a classe média emergente, e o próprio regime republicano. Surgiu daí a necessidade de criação de uma cidadania e de sua representação, e também de redefinição do povo, agora constituído por todos os elementos da população. A nação passa a ser debatida não só entre a elite letrada, mas também passa a fazer parte do projeto político estatal.

$\mathrm{Na}$ ausência de uma figura que personificasse o regime republicano, coube ao território este papel (MORAES, 2005). Unidade do território ainda era cultuada, mas naquele passou a ser questionada, também e valorizada, a diver- sidade desse território e sua integração. A unidade do território deveria contemplar também a unidade moral e social do país e a integração econômica. Nesse sentido, a escolarização ganhou um papel de destaque no período, pois ainda se colocava em questão a padronização da língua, a literatura nacional, a caracterização do povo, ou seja, uma integração nacional também simbólica (DUTRA, 2005).

Estes elementos, debatidos pela elite letrada, apareceram também nos livros didáticos de geografia do período. Pretendia-se uma educação cívico-patriótica, que ensinasse aos cidadãos o que era ser brasileiro e os valores e símbolos do novo regime. A geografia, que ainda não era institucionalizada no país, já possuía por mais de um século uma participação direta no cotidiano da nação, seja através dos institutos e sociedades, como o IHGB, seja como disciplinar escolar oficial com o currículo regulamentado e centralizado desde a criação do Colégio Pedro II. Por isso podemos afirmar que tanto os conhecimentos produzidos nos institutos quanto os produzidos na disciplinar escolar, participaram da consolidação e sistematização do conhecimento geográfico no Brasil, culminando em sua institucionalização na década de 1930.

Os livros didáticos eram portadores desses discursos da civilização, do progresso, e da modernização, todos inerentes a construção de um futuro ideal para o país. A imagem de Brasil elaborada por eles, poderia assim, formar as novas gerações em várias regiões do país.

Ao final da pesquisa, podemos então retornar à questão que as motivou: a ideologia nacional estaria presente nos livros didáticos de geografia e com eles estabeleceria uma relação interna? Constatamos que sim, pois como vimos os elementos considerados constituintes de uma nação estão todos presentes nos livros do período: o território, o povo, a língua, o passado comum, a religião. Cada um desses elementos foi destacado de forma a criar uma imagem da nação que se pretendia naquele momento. A afirmação da nação frente às 
outras, em um movimento de alteridade, mas também de pertencimento à sociedade moderna, também foi contemplado nos livros, e seu suporte era o ideal de civilização e progresso.

A formação da nação empreendida no período republicano em meio a debates delineou o que viria a ser o projeto de nação que se concretizaria no Estado Novo. Algumas dessas proposições permanecem e ressoam até os dias atuais.

\section{REFERÊNCIAS BIBLIOGRÁFICAS}

ANDERSON, Benedict. Nação e Consciência nacional. São Paulo: Ática, 1989.

BAKHTIN, Mikhail. Marxismo e Filosofia da Linguagem. São Paulo: HUCITEC, 1990.

CARVALHO, José Murilo de. A formação das almas: o imaginário da República do Brasil. São Paulo, Cia das Letras, 1990.

CARVALHO, José Murilo de. A construção da ordem: A elite política imperial; Teatro das sombras: a política imperial. Rio de janeiro: Civilização Brasileira, 2007.

CHAUÍ, Marilena. Brasil: mito fundador e sociedade autoritária. São Paulo: Editora Fundação Perseu Abramo, 2000.

CHOPPIN, Alain. História dos livros e das edições didáticas: sobre o estado da arte. Educação e Pesquisa, v.30, n.3., p. 549-566, set/dez 2004.

DOLHNIKOFF, Miriam. Elites regionais e a construção do Estado nacional. In: JANCSÓ, István. Brasil: formação do Estado e da nação. São Paulo: Hucitec, Ed. Unijuí, Fapesp, 2003.

DUTRA, Eliana de Freitas. Rebeldes literários da República: história e identidade nacional no Alamanque Brasileiro Garnier (1903 - 1914). Belo Horizonte: Editora UFMG, 2005.

EAGLETON, Terry. Ideologia: uma introdução. São Paulo: Editora UNESP: Editora Boitempo, 1997.
FERRAZ, Cláudio Benito Oliveira. O Discurso Geográfico: a obra de Delgado de Carvalho no contexto da Geografia brasileira - 1913 a 1942. 1994. 164 f. Dissertação (Mestrado em Geografia). FFLCH/USP, São Paulo, 1994.

GOMES, Ângela de Castro. A República, a história e o IHGB. Belo Horizonte: Argvmentvm, 2009.

GUIBERNAU, Montserrat. Nacionalismos: o estado nacional e o nacionalismo no século XX. Rio de Janeiro: Jorge Zahar, 1997.

HAIDAR, Maria de Lourdes Mariotto. O Ensino Secundário no Brasil Império. São Paulo: EDUSP, 2008.

HOBSBAWN, Eric; RANGER, Terence. A Invenção das tradições. Rio de Janeiro: Paz e Terra, 2008.

HOBSBAWN, Eric. Nações e Nacionalismos desde 1780: Programa, mito e realidade. Rio de Janeiro: Paz e Terra, 2008.

JANCSÓ, István; PIMENTA, João Paulo G. Peças de um mosaico (ou apontamentos para o estudo da emergência da identidade nacional brasileira). In: MOTA, Carlos Guilherme. Viagem incompleta: a experiência brasileira (1500-2000): formação, histórias. São Paulo: Senac: 2000. 127-175p.

LOURENÇO, Claudinei. A natureza no ensino de Geografia de $1^{\circ}$ e $2^{\circ}$ graus: perguntas ao passado. 1996. Dissertação (Mestrado em Geografia) - USP, São Paulo.

MAGNOLI, Demétrio. O corpo da pátria: imaginação geográfica e política externa no Brasil (1808 - 1912). São Paulo: EdUnesp: Moderna, 1997.

MORAES, Antonio Carlos Robert. Ideologias geográficas: espaço, cultura e política no Brasil. São Paulo: Hucitec, 1988.

MORAES, Antônio Carlos R. Território e História no Brasil. São Paulo: Annablume: 2005.

ORLANDI, Eni P. Análise de discurso: princípios e procedimentos. Campinas, SP: Pontes, 2009.

PEREIRA, Raquel Maria Fontes do Amaral. Da geogra- 
fia que se ensina à gênese da geografia moderna. Florianópolis: Ed. da UFSC, 1993.

ROCHA, Genylton Odilon Rêgo da. A trajetória da disciplina geografia no currículo escolar brasileiro (1837 - 1942). 1994. Dissertação (Mestrado em Geografia) - Puc-SP, São Paulo.

ROCHA, Genylton Odilon Rêgo da. Por uma Geografia moderna na sala de aula: Rui Barbosa e Delgado de Carvalho e a renovação do ensino de geografia no Brasil. Mercator/UFC, n. 15, p. 75- 94, 2009.

VEIGA, Cynthia Greive. História da Educação. São Paulo: Ática, 2007.

\section{Notas de Fim:}

1- As referências teóricas sobre a questão nacional são encontradas em: ANDERSON (1989); GUIBERNAU (1997); HOBSBAWN, Eric; RANGER, Terence (2008); HOBSBAWN (2008).

2- Neste artigo, trouxemos aproximações com a Teoria da Ideologia, a Análise do Discurso, e a História do Brasil e História da Educação no Brasil. As referências serão apontadas no texto.

3- Para a construção do contexto histórico da construção da nação e do Estado-Nação no período colonial, imperial e republicano brasileiros utilizamos como referencial teórico: CARVALHO, 1990; CARVALHO, 2007; CHAUÍ, 2000; DOLHNIKOFF, 2003; DUTRA, 2005; GOMES, 2009; JANCSÓ, PIMENTA, 2000; MAGNOLI, 1997; MORAES, 1988; MORAES, 2005.4- O sujeito "Eles" se refere aos representantes da Maripá e seus corretores (vendedores).

4-Sobre a educação neste período ver: HAIDAR, 2008; e VEIGA, 2007.

5-Sobre a Geografia Escolar no Brasil neste período: FERRAZ, 1994; LOURENÇO, 1996; PEREIRA, 1993; ROCHA, 1994; ROCHA, 2009.

6- Sobre a pesquisa em livros didáticos recomendamos a leitura de: CHOPPIN, 2004. Sobre os livros didáticos no Brasil: BITTENCOURT, 2008

7- No período da Primeira República 68 livros didáticos de Geografia foram publicados. Anteriormente, durante o Império, foram 42, sendo o primeiro em 1817 (LOURENÇO, 1996).

8- Neste artigo trataremos mais detalhadamente as duas primeiras categorias, deixando esta última, Povo e Cidadania, para outro momento.

9- As "recentes calamidades" sofridas pela França e a posterior adoção da geografia nas escolas fazem alusão ao episódio da guerra ocorrida entre França e Alemanha em 1870, quando a vi- tória alemã é atribuída ao ensino de geografia em suas escolas (PEREIRA, 1993).

10- Sem referências.

11- Pela ausência de qualquer referência, como o nome completo ou o livro a que se refere a citação, aparentemente trata-se do escritor e político português da Geração de 1870, Joaquim Pedro de Oliveira Martins (1845-1894).

\section{Correspondência da autora:}

Naiemer Ribeiro de Carvalho e-mail: naiemer@yahoo.com.br

\section{Artigo recebido em: 22/04/2015}

Revisado pela autora em:30/12/2015

Aceito para publicação em: 28/03/2016 